\title{
The Algorithmic Disruption of Workplace Solidarity
}

Citation for published version (APA):

Meacham, D., \& Tava, F. (2021). The Algorithmic Disruption of Workplace Solidarity: Phenomenology and the Future of Work Question. Philosophy Today, 65(3), 571-598.

https://doi.org/10.5840/philtoday2021519408

Document status and date:

Published: 01/01/2021

DOI:

10.5840/philtoday2021519408

Document Version:

Publisher's PDF, also known as Version of record

Document license:

Taverne

Please check the document version of this publication:

- A submitted manuscript is the version of the article upon submission and before peer-review. There can be important differences between the submitted version and the official published version of record.

People interested in the research are advised to contact the author for the final version of the publication, or visit the DOI to the publisher's website.

- The final author version and the galley proof are versions of the publication after peer review.

- The final published version features the final layout of the paper including the volume, issue and page numbers.

Link to publication

\footnotetext{
General rights rights.

- You may freely distribute the URL identifying the publication in the public portal. please follow below link for the End User Agreement:

www.umlib.nl/taverne-license

Take down policy

If you believe that this document breaches copyright please contact us at:

repository@maastrichtuniversity.nl

providing details and we will investigate your claim.
}

Copyright and moral rights for the publications made accessible in the public portal are retained by the authors and/or other copyright owners and it is a condition of accessing publications that users recognise and abide by the legal requirements associated with these

- Users may download and print one copy of any publication from the public portal for the purpose of private study or research.

- You may not further distribute the material or use it for any profit-making activity or commercial gain

If the publication is distributed under the terms of Article $25 \mathrm{fa}$ of the Dutch Copyright Act, indicated by the "Taverne" license above, 


\title{
The Algorithmic Disruption of Workplace Solidarity: Phenomenology and the Future of Work Question
}

\author{
DARIAN MEACHAM AND FRANCESCO TAVA
}

\begin{abstract}
AвstraCt: This paper examines the development and technological mediation of the concept of solidarity. We focus on the workplace as a focal point of solidarity relations, and utilise a phenomenological approach to describe and analyse those relations. Workplace solidarity, which has been historically concretised through social objects such as labor unions, is of particular political relevance since it has played an outsize role in the broader struggle for social, economic, and political rights, recognition, and equality. We argue that the use of automated decision support systems (ADS) in labor process management may negatively affect the formation of these relations. As solidarity motivates collective political action and risk-taking, the mediation and potential obstruction of solidarity relations by ADS is politically significant. We contribute to the growing literature on the "future of work" problem in elucidating the technological mediation of workplace solidarity.
\end{abstract}

KEY wORDS: Solidarity, future-of-work question, phenomenology, technological mediation, social objects, algorithmic decision support systems, platform labour

\section{INTRODUCTION}

The "future-of-work" question in a nutshell pertains to the "significant changes" in the "world of work" that are correlated with the increased prevalence of digital, and specifically data-driven and machine learning technologies (JRC 2019: 6). The impact of these technologies is raising concerns about technological unemployment, ${ }^{1}$ polarisation ${ }^{2}$ of the labour market in technologically developed countries, and, more broadly, the transformation of historical structures and forms of working life (Frey 2019, EuroFound \& ILO 
2017). The latter includes increases in independent contracting, platform work, job precarity, etc. As structures and forms of working life have an enormous influence on nearly all other aspects of social and individual life (down to when, where and how people eat, sleep, have and raise children, etc.), the "future-ofwork" question is not a narrow sectoral issue. It touches upon nearly all aspects of the lifeworld (we use this term in a broadly phenomenological sense as the world that is collectively or intersubjectively experienced as objective): family structure, education, and organisation of political structures. ${ }^{3}$ "To think about the future of work is to think about the future of our societies" (EGE 2019).

Our focus in this paper is more narrowly on changes to the intersubjective experience of work. Our approach is broadly speaking phenomenological, that is, we are concerned with specific ways in which changes in the world of work impact the subjective and intersubjective experience of working life. We approach this theme both historically and in relation to the increased use of data-driven and machine learning technologies in the form of automated or algorithmic decision support systems (hereafter ADS) in the organisation and management of work. Specifically, we focus on solidarity as a particular type of intersubjective relation that potentially emerges within specific socio-technical contexts. As such, it can be phenomenologically characterised as having a specific motivational and affective structure, and delineated from other types of experience, and subsequently from similar political concepts, e.g., sympathy or charity. We argue that in democratic societies solidarity relations are an important political desideratum insofar as they motivate and facilitate collective action, risk-taking and longer-term political consideration and planning. In this sense, we consider solidarity a social good as well as an individual good.

While solidarity relations can and do emerge outside of the specific context of workplace solidarity, the latter has historically been one of the, if not the, most significant loci for the formation of solidarity relations. Subsequently, changes to the way that solidarity relations form (or don't) in the workplace have a broad societal significance that mirrors the broader societal significance of the futureof-work question. The conceptual and historical accounts of workplace solidarity developed in parts 2-4 of the paper are significant in their own right in establishing the technological mediation of workplace solidarity, and also necessary to the argument and analysis in part 5 where we examine the contemporary context and, more specifically, the impact of ADS. The aim of this paper is to develop the concept of solidarity as sketched above and investigate how ADS may affect the formation of workplace solidarity relations. While we point to concrete cases, and small-scale ethnographic research on the topic, our argument is largely speculative and normatively speaking a call for attentiveness. Capitalist firms have long used technological and organisational means to disrupt the formation of solidarity relations. ${ }^{4}$ These attempts at disruption have historically taken various forms, 
including legal and legislative impediments to the formation of certain kinds of social objects (e.g., unions), physical disruption of strikes, meetings, etc., and the organisation of work processes in such a manner as to inhibit the formation of solidarity relations and supporting social objects. Our analysis contributes to the examination of these forms of disruption.

Building on their previous work on the concept, Prainsack and Buyx (2017, 2018) have approached the future-of-work question from a solidarity framework within the context of health inequality and societal well-being. They note a wellestablished correlation between "job insecurity, marginal or informal employment, loss of employment and long-term unemployment" and a negative impact on "health and well-being" as well as the relation between social status (often linked to employment) and health. Defining solidarity as "enacted commitments to accept costs to assist others with whom a person or persons recognise similarity in a relevant respect" (Prainsack and Buyx 2017: 52), they argue for solidarity as a pre-condition for social cohesion. Their concern is that technological unemployment stemming from digitalisation could negatively affect "the recognition of similarity with others, which is vital for any solidaristic practice" (Prainsack and Buyx 2018: 589). The recognition of similarity that they contend is created by employment in modern economies is linked to the idea of workers as contributors to a heavily interdependent network of differentiated economic and social roles and relations. Their concern is that those who do not work in what is currently regarded as economically productive employment will be considered free-riders, to whom the "productive" members of society have diminished obligations. If that group grows due to technological unemployment it will facilitate increased (in number and size) cleavages of social cohesion. As a response to the threat to social cohesion posed by technological unemployment, Prainsack and Buyx argue for a reconsideration and revaluing of the interdependent concepts of work and social productivity or contribution.

While we generally agree with Prainsack and Buyx's analyses and suggestions, the argument and analyses that we offer here differ in several significant respects. First, while we realise the threat posed by technological unemployment, especially if it becomes structural, and job polarisation, our argument is independent from an analysis of these phenomena and their existence. While polarisation is more or less an accepted given, the degree of technological unemployment, present and future, due to digitalisation is a matter of debate in academic and industry literature (Acemoglu and Restrepo 2020). Our focus instead is on the technological mediation of the formation of solidarity relations within the workplace. This has broader consequences, and how the threat of technological unemployment and the reality of polarisation are politically addressed may depend on the potential for forming solidarity relations within the workplace. Second, for reasons that we will elaborate below, we understand solidarity, in the normative sense that we wish to elucidate, 
to be explicitly political in its aims and also require an experience of (at least) expected potential reciprocity. Our understanding of solidarity is thus narrower than Prainsack and Buyx's. Third, while we agree that "solidaristic practice can happen at any social level or 'tier,' ranging from transient solidaristic interactions between individual people, to more institutionalized group solidarity practices, to solidaristic arrangements in the form of legal, contractual, or administrative norms and rules (e.g., universal health insurance, progressive taxation, etc.)" (Prainsack and Buyx 2018: 588), we also want to place emphasis on another, phenomenologi$\mathrm{cal}$, aspect. Certain types of social objects, labour unions being the paradigmatic example, support, solidify and reify solidarity relations between subjects.

Below, we first elaborate and further justify our focus on solidarity relations within the workplace. Second, we argue that solidarity is a political desideratum in a democratic society. Third, we propose a phenomenological account of solidarity that we think allows solidarity to be distinguished from other similar phenomena in a relevant manner. Fourth, we examine how the use of ADS in the workplace may affect solidarity relations.

\section{WORKPLACE SOLIDARITY}

This article builds on the premise that a tight connection exists between the concepts and practices of solidarity and work, the latter comprising work (in the sense of employment) as well as the intersubjective and societal aspects that the activity of working involves, such as competing, collaborating, and unionising. ${ }^{5}$ The (rather short) history of the concept of solidarity supports this premise. Unlike other ideas often related to it, such as justice and freedom, solidarity became a central topic in the public debate, and subsequently in social and political theory, only in the aftermath of the French Revolution. The idea subsequently developed throughout the nineteenth century in correlation with the rise of industrialisation and workers' movements. Commenting on the emergence of solidarity in European history, Metz (1999) emphasized that one of the lasting achievements of the French revolutionary era was the creation of horizontal mutual aid structures between citizens. The radical equality that the Revolution had introduced allowed people to collaborate and mutually support each other as peers, and not on the basis of hierarchical structures whereby those with a higher status charitably decide to provide aid to the poorer. This new form of mutual and gratuitous collaboration, which is at the basis of what we call solidarity, crystallised in the nineteenth century in the form of solidarity among workers. That is, between individuals united not by any inherited status or privilege, but by the simple fact that despite their differences they all draw sustenance from the same fundamental activity_labour-and are therefore willing to combine their efforts in the struggle between labour and capital. ${ }^{6}$ 
The first theoretical accounts of solidarity, which emerged in the late nineteenth century, reflect the central role that work and the workplace had in its practical formation. Durkheim's social theory is in this sense particularly relevant as it directly connects the evolution of the concept of solidarity with the social and technological changes that the activity of working had gone through in late modernity. Whilst pre-modern societies were characterised by what Durkheim calls "mechanical solidarity" (or "solidarity by similarities," Durkheim [1893] 2013: 57), i.e., by an extremely cohesive social integration based on shared values, beliefs, and ways of life, the division of labour triggered by industrialisation fundamentally modified this picture and introduced a new form of "organic solidarity" (Durkheim 2013: 88). With work activities becoming more and more differentiated and specialised, workers started to develop different skills and increasingly differ from one another. At the same time, because of this differentiation and specialisation of activity, they also started to depend increasingly on one another, and therefore they found themselves in need of establishing solidaristic relations of mutual aid and support in order to guarantee their survival. In other words, whereas the trigger of mechanical solidarity was the tight cohesion of homogenised traditional societies which prevented the emergence of autonomous individualities, organic solidarity does not stem from this unbreakable unity but rather from the specialisation and differentiation of its components. Like bodily organs, which sustain each other and contribute to the survival of a living organism by performing different yet interrelated tasks, individuals in modern societies form a complex web of collaborations and dependencies and, by doing so, despite their apparent differences (or because of them), pave the ground for a new type of solidarity.

As Durkheim showed, the evolution of work modified the way in which individuals established solidarity bonds. However, the opposite may also occur whenever spontaneous phenomena of solidarity among workers solidify into more stable social objects-e.g., unions, social regulations, laws-whose function is to facilitate the provision of mutual aid in order to prevent conditions of exploitation and suffering, and consequently to alter working conditions and structures. ${ }^{7}$ In this sense, if it is clear that solidarity relations are socially and technologically mediated, which means that we cannot address them without considering the contextual constraints that their emergence and implementation entails, it is also clear that, once established, solidarity can itself become a mediator as it impacts on the way in which society and technology evolve and interact.

Solidarity relations and institutions have also been for workers in the nineteenth and twentieth centuries the primary means of gaining political leverage and securing rights concessions. Liberalism in economic thinking did not lead organically to democracy. The marriage of the two with universal suffrage was in many instances the result of sustained solidarity actions (strikes) wherein portions of the working population withdrew labour from the economy as a way of gaining 
political leverage and concrete rights concessions (Hobsbawm 1975, chap. 6; see also Sack 2018 for an account of the use of strike action to secure the franchise). This circumstance seems to contradict the common view that solidarity is not a fundamental civic obligation-something that must be established and disseminated in order to enable social justice-but rather a practice that belongs to the axiomatic, supererogatory realm, i.e., something that, although it is generally considered laudable and worthy, per se is not required by justice and therefore cannot be mandated. ${ }^{8}$ The infrastructural role that solidarity played in the nineteenth and twentieth century in ensuring fundamental liberal rights (e.g., right to vote, limited working hours, working week) suggests that solidarity has played more than a mere ancillary function in modern social and political life. It is probably true that solidarity is an axiomatic and not a deontic principle, insofar as it cannot be detached from the contexts and experiences from which it stems, and cannot therefore be considered as a universal, "a-historical" principle. Nonetheless, its historical development seems to confirm its status as "a prerequisite of justice" (Gould 2014: chap. 6) or "the reverse side of justice" (Habermas 1990: 47). We think this is particularly manifest in the case of workplace solidarity where the creation of stable solidarity-groups of workers that are built around the needs of resisting perceived injustice and defending vulnerable members-prepared the ground for a fairer society and, therefore, helped shape a more substantive and functional idea of justice.

\section{Solidarity: A Political Desideratum}

The above shows how solidarity among workers has historically empowered individuals and groups to generate political action, respond to conditions of inequality and injustice, and ultimately ensure liberal rights. At least two factors trigger this mechanism and set solidarity in motion.

(1) First, in order for people or institutions to form this kind of solidarity, they must share certain political goals and ideals as well as be able to perceive injustices committed against others (as well as themselves). Being workers is not a sufficient condition to generate solidarity relations. In addition to acknowledging their shared status qua workers, solidarity bonds (as we conceive them) require collectively aiming to overcome perceived inequalities or injustices. ${ }^{9}$ In this regard, the presence of a corporeally inhabited workplace, i.e., of a space where people can perceive and communicate with one another and subsequently cooperate, generating the conditions for social struggle and change, can be seen as an important facilitator for the identification of shared political goals and therefore the establishment of solidarity relations. Similarly, the absence of face-to-face contact between workers can potentially hinder the emergence of such relations. This assumption underpins the ideology of the First International, which aimed 
at "combining and generalising the till now disconnected efforts for emancipation by the working classes in different countries" (Resolutions of the Congress of Geneva, 1866: 3). What unites workers in solidarity relations is not their being similar, the fact that they belong to the same social class, but their willingness to struggle in order to fight oppression and defend the rights of this class. This notion of solidarity places primacy (both historically and normatively) on shared agency rather than on any mere sense of identity or belonging. Arendt's account of solidarity seems to be in line with this characterisation of the embodied dimension of solidarity as significant for the formation of a community of "interest." She argued that solidarity stems from the perception of others' suffering, in response to which a community of interest is formed. Arendt maintains, however, that although solidarity may be aroused by suffering, it is not guided by it since "it remains committed to 'ideas' - to greatness, honor, and dignity" (Arendt 1990: 89).${ }^{10}$ In Arendt's view, this distinguishes solidarity from emotions such as pity and compassion, which although might enable its formation are essentially detached from it insofar as, unlike solidarity, they do not partake of reason, and hence of generality, and are not necessarily political.

(2) Second, the sharing of a determined political agenda depends on the willingness of individuals and groups also to share the costs and burdens of this agenda with at least an expectation of reciprocity. This characteristic refers back to the legal and economic origin of the notion of solidarity (the concept of solidus in Roman law, referring to shared responsibility for debts), and helps to again differentiate solidarity from other intersubjective relationships such as sympathy, benevolence, and charity (more on this later). For instance, when workers decide to establish a mutual relationship of solidarity, they know that this action has consequences that might be detrimental (i.e., job loss, discomforts due to prolonged striking, etc.), and nonetheless decide to act anyway and to equally share the burden of these potential consequences. Again, we contend that this factor might also be lacking, should the workforce lose cohesive face-to-face contact and be rather scattered and progressively atomised across the social fabric. It is arguably harder to share costs and burdens with people and groups with which we maintain only indirect virtual relationships.

Moreover, we can also argue that (1) motivates (2), i.e., it is this sharing of political goals or ideals that foments the willingness to also share costs and risks with an eye toward longer-term gain and increasing probability of achieving the shared goals. The willingness to shoulder burden and take risks in the aim of potentially longer-term political and social-economic goals is furthermore supported, in a virtuous circle, by the sharing of the risk, which can also mitigate individual risk. Thus solidarity facilitates collective decision-making (as it is a political relation among equals), collective action (as it mitigates individual risks through risk sharing), and longer-term political action and planning (through 
collective decision-making, action, and risk/burden sharing), all characteristics that can be described as desiderata within a democratic society. Solidarity is thus not just a descriptive notion that indicates a certain form of human togetherness, but a fundamental or infrastructural dimension of democratic life. Subsequently, a democratic society should seek at political, legal, and social levels to foster forms of solidarity (and those institutions that concretise solidarity relations) in order to better uphold and develop its internal mechanisms and cohesion.

While this characterisation applies to at least some cases of workplace solidarity, one can ask if it also applies to solidarity as such. In other words, is solidarity a political desideratum regardless of how and to what end this relationship is established? The answer to this question is no. In order to determine whether a specific form of solidarity can be counted as a political desideratum, it is necessary to consider its ethical and political setting. In other words, it is necessary to clarify what motivations bring members of a group together, what drives their collective action, and at what cost they are willing to protect and implement this togetherness. This kind of scrutiny can easily identify examples of "bad solidarities," i.e., quasi-solidaristic intersubjective bonds that are not driven by any clear democratic ideal, but, for instance, the social or political advantage of its own members over others. Scholz (2008: 46) uses the term "parasitical solidarity" to indicate cases where aspects of solidarity relations may be present, but are used instrumentally to advance the interests of individuals or sub-groups within a set of purported solidarity relations. Solidarity bonds might also be present between individuals pursuing universalisable but undemocratic political aims (and methods). Bonds of solidarity could, for example, emerge among the members of terrorist groups and fulfil what we think to be the necessary criteria for being defined solidaristic, while also clearly not aiming toward an outcome that is beneficial to a democratic society; this does not preclude the relations in question being characterised as solidarity.

Other cases point to relations that are often rhetorically identified as solidarity, but which we think should not be counted as such. For instance, when people claim that they feel "in solidarity" with the victims of a terrorist attack or natural disaster half a world away (or closer). What they usually mean is that they express sympathy towards them. However touched they may be by what happened (and therefore sympathetic with the victims), they are in fact unable or unwilling (1) to engage in collective action or (2) to engage in reciprocal cost-bearing or risk sharing, which we take as two fundamental conditions for solidarity both historically and in terms of conceptual coherence.

We agree with Scholz that parasitical and rhetorical solidarity do not qualify as solidarity relations properly speaking, while nonetheless having some of their characteristics. We think, however, that in some cases of un-democratic solidarity (e.g., solidarity of terrorists), some bullet biting is necessary in recognising that while solidarity may be a desideratum in democratic society, there can be forms 
of it that are not conducive to democratic ideals or society or even interested in that at all, while nonetheless fulfilling the other criteria.

Workplace solidarity is not immune from parasitical uses. The formation of a "labour aristocracy" in industrialised countries throughout the nineteenth century is an example of this phenomenon (Hobsbawm 1964, chap. 15; Gray 1981). ${ }^{11}$ Workers with higher incomes and better living standards formed this "aristocracy," which although it formally belonged to the working class and purportedly struggled to defend universal rights in a spirit of solidarity with fellow workers, in reality followed a conservative political agenda, which aimed at maintaining acquired privileges rather than at promoting social change. Different political goals, and an apparent disparity of costs and risks that these goals incurred, indicate the parasitical character of solidarity between so-called "labour aristocrats" and lessadvantaged workers. Although the phenomenon of labour aristocracy is typically ascribed to the second half of the nineteenth century, many interpreters identify contemporary manifestations (Cope 2012; Kerswell 2019). These arguments have often taken the form of critical accounts of Eurocommunism and social democracy, whose proponents are accused of relying on the privileges that they derived from global imperialism, in whose framework they play the role of a world labour aristocracy at the expense of the working classes in underdeveloped countries.

The example of labour aristocracy highlights the inner instability of solidarity relations. These relations can undergo substantial modifications, and potentially lose their character of political desiderata when solidarity relations become cover or instrumental for advancing particular group interests. Social and technological factors can modify the relations between solidarity groupings and the external (to the solidarity grouping) social world, modifying their structure from nonparasitical solidarity groups to parasitical solidarity/interest-groups. In the case of nineteenth-century labour aristocracy, these factors included the emergence of urbanisation and division of labour in industrialisation to include a managerial working class. This allowed a small section of the working class to acquire new roles and responsibilities and start a process of gradual embourgeoisement, which made their solidarity relations with less-advantaged workers parasitical. The same phenomena that, as Durkheim showed, made possible the creation of modern solidarity (division and specialisation of labour) is also what threatens the validity of this form of solidarity. The same risk occurs nowadays in light of the emergence of new technologies, which threaten to create at the same time new forms of solidarity as well as further divisions and conflicts among different layers of the working class (more on this in the fifth section). In light of this complexity, in order to maintain the assumption that solidarity is a political desideratum as long as it meets certain criteria (shared goals/ideals of justice, equal sharing of risks and costs), it is important to clarify how solidarity takes shape, what factors can mediate its formation, and how can we make good use of it. 


\section{Solidarity: A Phenomenological Account}

In the previous two sections, we have (1) justified our specific focus on workplace solidarity by identifying the world of work, historically speaking, as the locus for solidarity relations that have broader societal scope and ramifications, especially in relation to the securing of social and political rights; and (2) argued that solidarity is a political desideratum as long as it facilitates essential characteristics of democratic life (collective decision making and action, collective risk taking in the aim of longer-term democratic political goals). We have also argued that the politically desirable form of solidarity, to be a meaningful political concept that can be clearly distinguished from other relevant concepts such as sympathy and charity, must be both reciprocal in its nature and be formed on the basis of political agency-similarity. That is, the recognition of similarity that underpins the shared risk and cost bearing proper to solidarity relations is a similarity of motivation and agency that arises in particular situations, namely political ones (characterised by a legal and institutional structure). In such situations, the agency is offensively directed towards the political structure and aims at addressing injustices stemming from that structure (on the "offensive character" of solidarity, see Habermas 2013). Moreover, we have argued that this characteristically modern understanding of solidarity emerged in a specific socio-technical context characterised by urbanisation, industrialisation, the division and fungibility of labour, and the specification and inter-dependence of roles and tasks. We have also seen that this characterisation of solidarity can run up against a series of setbacks that threaten to undermine its stability, and turn it into a form of rhetorical or parasitical solidarity. We also maintain that the experiential or phenomenological dimension is constitutive of the concept, not just descriptive, i.e., that solidarity is a type of intersubjective experience. Addressing solidarity phenomenologically has the advantage of clarifying how socio-technical objects that might modify its meaning, value, and intensity mediate its emergence. Furthermore, a phenomenological analysis of solidarity allows us to obtain a more fine-grained definition of the concept, and to distinguish it from related ideas such as sympathy and charity.

The phenomenological characterisation of solidarity as we describe it has at least five fundamental aspects (we do not claim to have an exhaustive list or account here, but a necessary one).

\subsection{Motivational Character}

Solidarity relations are characterised motivationally by a normative force, i.e., they are concurrent with an experience of responsibility for the other with whom one is in solidarity. The experience of responsibility motivates the cost and risk bearing on the other's behalf. What is significant is that the experience 
of solidaristic responsibility is independent of prior relations or shared affiliation with the other(s). It is impersonal and co-emergent with the solidarity relation itself and thus has as a sufficient condition the shared political agency described above, commitments aimed at a legal/political institutional structure, and the characteristic of experienced risk and reciprocal cost bearing (see 4.2 and 4.3 below). Sufficient does not mean exhaustive; the similarity of political agency may be accompanied by other forms of similarity, but these are not required.

\subsection{Perception of Risk}

Solidarity qua experience entails a perception of risk that we have also called cost-bearing. This perception of risk distinguishes the experience of solidarity from sympathy or charity, wherein one may be affected and/or take action to aid another, but may do so without any perception of risk to themselves. We emphasise the perception of risk as important here, as solidaristic actions may not actually incur risk, which is futural and hence uncertain. This is why the phenomenological characterization of the relation is important; certain aspects must be understood as perceived and not necessarily actual.

\subsection{Horizon of Expected Reciprocity}

We have argued above that (cf. Prainsack and Buyx 2017) solidarity should be distinguished from other similar concepts (sympathy, charity) by the requirement of expected reciprocity. This means that a horizon of expected and predictable reciprocity characterizes the experience of solidarity. That the reciprocity is only required to be expected and not actual allows for greater scope and durability in solidarity relations; and makes the experiential content constitutive. We think however that it must be perceived as predictable in its expectability; reciprocation as experienced qua possibility on a futural horizon cannot be capricious. This provides the required durability for risk-taking or cost bearing on another's behalf (on the durability of solidarity relations, see also Kolers 2012). The phenomenological criterion of expected reciprocity (we experience the expectation of the reciprocity, not the reciprocity itself) makes it such that acting in solidarity is not a purely altruistic relation. One does not act solely for the other, but always also for one's own (potentially future) benefit. The expectation can be disappointed, if and when the risk-taking and cost-bearing is not reciprocated. This may make future experiences of solidarity with the non-reciprocating person(s) less likely, but it does not invalidate the initial experience of solidarity, precisely because we have characterised the relation phenomenologically.

\subsection{Boundary Conditions}

The horizon of a perceived expectation of predictable reciprocity also sets certain boundary conditions to the scope or breadth of solidarity relations. By the work- 
ing definition that we have provided here, it is not possible to establish solidarity relations with those persons with whom you cannot have an expectation of predictable reciprocity. While the horizon of expected reciprocity sets boundary criteria for solidarity relations, universal solidarity can nonetheless function as a regulative ideal. Habermas (2013) refers to this as "the humanist generalisation ... of the [Judeo-Christian] intuition that one's own local community is part of a universal community" (9). Beyond the examples of proselytising religions, one can point to social movements such as the IWW (Industrial Workers of the World) as having a near universal boundary condition. However, even the idea of universal human solidarity requires an exclusion criterion, namely what is not human. Following from point 3 , boundary conditions are experiential and subjective, i.e., they are constituted by a subjective horizon of expected predictable reciprocity and not by objective conditions of whether reciprocity has actually been enacted or not.

\subsection{Social Objects}

The solidarity relation itself can be instituted as a social object, i.e., constituted as a thing in the world through reciprocal communicative acts. Like a friendship, a solidarity relation can be perceived as something that stands outside of the subject and hence can be worked on, perceived by others (not in the relation), etc. As a social object, the solidarity relation, continuously reinstituted in subjective experience by communicative acts, has duration, can achieve levels of robustness, and exerts a motivational force upon other subjects and objects around it. In the case of the solidarity relation as social object, that motivational force is normative. It motivates the subjects constituting the relation to continue to reciprocate responsibility qua burden sharing. As this is itself a communicative gesture, it serves to re-institute the social object. This is why, for example, Hobsbawm (1952) argued, that the "habits of solidarity ... take time to learn." Communicative contact between subjects is a requirement for the formation of solidarity relations as social objects and for their normativity to become habit. Blocking or otherwise stifling this communicative contact is a manner of suppressing the reification into social objects which lends duration and robustness to solidarity relations, as well as making them potentially more resilient to disappointment-the social object remains, at least temporarily, independent of the actions of the subjects whose communicative actions it does ultimately rely upon. This reinforces the socio-technical mediation of solidarity relations. They can depend on or at least benefit greatly from a technical context that facilitates communication as well as the perception of another's suffering, one of the motivating factors for solidarity formation.

Solidarity relations can also be supported by other social objects. The class of objects of which we might say unions, clubs or even nations are paradigmatic 
institutionalised forms, can serve as poles of subjective affiliation and identification (affiliation is experienced as partially constitutive for the participating subject) that can but do not necessarily precede solidarity relations. What they can do is to include solidarity with other fellows as an affiliation condition such that solidarity relations and the consequent solidarity social objects are nested within them in a contingent and supporting fashion. These supporting social objects may provide the necessary framework for the prolonged communicative action that solidarity as a social object requires (while themselves also being dependent on forms of communicative or gestural action). In cases where the supporting object is capable_institutionally/legally speaking—of inserting itself in a political context, the object may have even greater affinity for supporting or reinforcing the solidarity relation, but it is not strictly speaking necessary. The supporting social object as a pole for solidarity relations also can have the effect of solidifying those relations by creating boundary conditions and exclusion criteria. Participation in the communicative constitution of a political social object (what we could also call membership in a political association, official or not) demarcates who (likely) merits reciprocal solidarity relations and who does not. It also lessens the possibility of disappointment or non-reciprocity of solidarity relations, and makes those relations more resilient against disappointment. The boundary conditions and exclusion criteria formed by participation in the constitution of a political social object also prevent the potential dilution or over-generalisation of solidarity relations. That these kinds of social objects facilitate and shore up solidarity relations does not preclude that such relations cannot occur outside of them, but they serve to stabilise and, in some cases, formalise these relations. It may be the case that the expectation of solidaristic reciprocity is formalised in the communicative activities entailed in the constitution and maintenance of a supporting social object, which may involve, for example, an active and explicit affirmation of willingness to actually reciprocate solidarity relations.

Three points to conclude this section: First, solidarity relations are intersubjective and in part constituted by experiential content. These relations can be reified or concretised as social objects that are historical constituents of the lifeworld. Solidarity relations become objective things in the world that alter the way that the world is experienced. Solidarity could be compared to love and friendship in this sense (all may have a biological as well as historical dimension). Second, the appearance of solidarity relations and their reification into social objects is technologically mediated. Certain socio-technical contexts or arrangements will have a greater affinity for the type of sustained perceptual and communicative content conducive to solidarity than others. Third, the normative dimension of our argument is conservative. We consider solidarity as a historically developed and technologically mediated desideratum. It is valuable; we have a political concern about changes in the socio-technical context that would lead to less of it. 


\section{Solidarity and Automated Decision Systems}

In this section, we return to the future-of-work question, introduced in the opening paragraphs. Our question is, given that modern socio-technical phenomena (urbanization, industrialization, division of labour) have changed solidarity in the past, how will a socio-technical context characterised by an increasing prevalence of ADS in the world of work potentially affect the possibilities for the formation of solidarity relations. While process automation is more commonly linked to concerns about technological unemployment, our question pertains to the changing structure of the experience of work. As Algorithm Watch notes, "Algorithmically controlled, automated decision-making or decision support systems are procedures in which decisions are initially-partially or completely-delegated to another person or corporate entity, who then in turn use automatically executed decision-making models to perform an action" (Algorithm Watch 2019: 9). ${ }^{12}$ Within ADS, decisions are made or suggested on the basis of analysis of historical data either collected within the system itself or fed into the system as "training data." The term decision in this context refers to the selection or ranking of options (actions, products, interpretations). ADS replace analyses, judgements and decisions that would otherwise have been made by humans or offer support for human decision-making in the form of recommendations and parameters. Within the broader future-of-work debate, discussion about the ethical and societal impact of ADS concern the automation of largely cognitive tasks, whereas previous discussions have revolved around the replacement of physical tasks (Mittelstand et al. 2016). In relation to the formation of solidarity relations, historically speaking both forms of automation are clearly relevant.

The use of the term system, rather than technology, is significant here as the impact of an ADS cannot be abstracted from its placement and use within socio-technical systems which includes humans, artefacts, rules and regulations governing human-to-human and human-to-artefact relations, and a broader institutional context governing the use of data. ${ }^{13}$ Not all ADS need rely on computer algorithms, but in the contemporary context ADS generally make use of computer algorithms. The use of data-driven ADS is ubiquitous and varies in terms of human involvement in the decision-making process; hence a distinction between autonomous decision-making systems and semi-autonomous decision support systems. For example, the recommendations put forward by an Amazon, Netflix or Spotify, support a purchasing decision on the part of the user by prioritising the products presented on the basis of user history and association (what products users who have made similar past decisions have selected) and structuring choice architecture accordingly. The decisions as to what should be recommended are made autonomously without human input. ADS are also used in many aspects 
of (European) public governance including "automated processing of traffic offences ... allocating treatment for patients in the public health ... automatically identifying which children are vulnerable to neglect" (Algorithm Watch 2019). Well-known cases of algorithmic decision support in the criminal justice system include the COMPAS Recidivism Algorithm (Larsen et al. 2016) in the United States and automated welfare fraud detection in the Netherlands (ruled to be in violation of European Human rights law). ${ }^{14}$

The use of ADS within the workplace differs depending on the structure of the firm and the work context. In the case of paid tasks mediated by digital platforms, the use of ADS has allowed for firms to attempt to redefine their legal and social roles vis-à-vis workers (qua employees or contractors) and the notion of the workplace and workspace itself (see EuroFound 2018 for a detailed description of the types of platform work in the EU). Within more traditional employment settings-e.g., distribution and logistics centres-ADS are also used to distribute tasks and manage workflows as well as for evaluation of worker performance and suggestions regarding worker retention (hiring and firing) (Leicht-Deobald et al. 2017). Our aim is not an exhaustive account of the use of ADS in controlling workers or suppressing labour activism but rather an overview of how the use of ADS might intentionally or unintentionally disrupt the formation of solidarity relations in the manner that we have characterized them in the preceding section.

Ethical analyses of ADS tend to focus on impacts to individual rights or wellbeing, specifically fairness (Mittelstadt et al. 2016; Jaume-Palasi \& Spielkamp 2017). These analyses usually place focus on issues such as transparency, accountability, explainability. These are important, but not adequate to addressing the impact on social phenomena such as solidarity, especially when that impact is legal and intentional, and works by degrading affinities that solidarity relations emerge from. Solidarity is not treated either ethically or legally as an individual right in the fashion of privacy; although the right to form labour unions may be seen as a "solidarity right" insofar as labour unions have historically institutionalised and concretised solidarity relations. The concern about the impact on solidarity relations is more a "transformative" concern (cf. Mittelstadt et al. 2016; Floridi 2014); it relates to how the world is conceptualised and experienced rather than a violation of a right. As Mittelstadt et al. show, transformative concerns in the literature focus primarily on the impact on individual autonomy (from, for example, personalisation in recommender systems) and information privacy. Koening (2019) has argued that ADS do not just pose a threat to the autonomy or other rights of individual persons, but rather that artificial intelligence (which we take as a proxy term for ADS) calls into question the enlightenment notion of the autonomous individual which underpins modern social and political structures. Koening's basic thesis supports Floridi's argument that ADS potentially "reontologises the [human] world" by reshaping its fundamental entities, e.g., individual 
persons. Our concerns here tread something like a middle ground. We think that the social and political impact of ADS goes beyond issues concerning individual autonomy or privacy rights (which nonetheless take the potentially autonomous human individual as a presupposition in ethical and political consideration), while we remain non-committal here about a reontologising of the human world such that the idea of the individual is called into question altogether. The focus of our concern regarding ADS follows from what we have argued above that solidarity is a significant experiential feature of the social and political dimensions of the lifeworld and may also play into other subjective experiences, like the perception of risk and uncertainty. In this sense technological changes that make solidarity relations less likely to emerge are transformative of the lifeworld.

In the following paragraphs, we use labour platforms as one case of the impact of ADS on the conditions of solidarity formation. ${ }^{15}$ The phenomena that we describe here are however not limited to interactions and relations on these platforms. Leicht-Deobald et al. (2017), have, for example, argued that the use of ADS in human resource decision-making in traditional firm structures, may have the effect of limiting "personal integrity" understood in terms of human ability to make sense of one's own decisions, behaviour, and actions and encouraging compliance with existing organisational norms and cultures. As we have described solidarity relations as having a decisional and oppositional structure as part of their motivational or experiential character, the phenomena that Leicht et al. describe would potentially have a chilling effect on the formation of workplace solidarity relations.

A direct example of algorithmic management impacting the formation of institutionalised solidarity relations pertains to the legal employment status of labour platform workers. There are ongoing legal and policy debates in North America and the EU concerning the legal status of platform workers; having the status of independent contractors and not of employees precludes participation in collective bargaining agreement processes, and legally recognised labour union formation. ${ }^{16}$ While these debates can be understood as continuation of outsourcing and subcontracting trends that pre-existed today's algorithmically governed labour platforms (Srnicek 2017: 82), the use of ADS to allocate tasks ("gigs") to platform labourers allows for the "flexibility" and rotation/substitution of workers that labour platforms and some courts have argued make such labourers not-employees. Court decisions in Italy, France, USA, and UK have justified decisions to not classify "gig" workers as employees on the grounds that they were free to take or refuse shifts or tasks, to sign off and on: "work when they want to and are free to nap, run personal errands, or take smoke breaks between trips" (DeStefano 2018). ${ }^{17}$ This "freedom" - called into question by conflicting rulings-is facilitated by the ADS that govern the allocation of tasks on the platforms in question and would not be possible without it. The classification as independent contractors has been 
used in some legal jurisdictions to deny union representation to platform workers (see Prassi $2018^{18}$ ). In addition to the obvious legal and political significance of union representation and collective bargaining rights, we have argued above that social objects-with labour unions being the paradigmatic example-function as important poles of stabilisation for solidarity relations, providing an institutional framework for collective action, deliberation, and reciprocal burden sharing. ${ }^{19}$

The use of ADS in the intentional or unintentional suppression of solidarity relations extends beyond legal impediments to social object formation and subsequent collective bargaining rights. We have argued above that solidarity relations are social objects and can also be reinforced by other social objects. The roles of perception, gesture and communication as bodily and moreover intercorporeal phenomena are important here.

ADS allow labour platforms to disperse workers globally and do away with a need for a "workplace" with a stable workforce that perceptually and corporeally interacts on a regular basis; a condition that reinforces both fundamental factors of solidarity relations (i.e., the presence of shared goals and ideas, and the willingness to share costs and risks). The obstacle that this lack of a "workplace" poses to labour organising is well documented in the literature: "Isolated as so many of them are, on-demand workers rarely meet face to face, and online forums are a second-best substitute for building trust and solidarity. Sometimes when these workers communicate online, companies spy on them-and even kick potential troublemakers off their platforms" (Greenhouse 2016). The challenge is exacerbated when a platform workforce is globally dispersed. On the basis of their survey work, Graham et al. (2017) report:

Our research shows that some workers feel detached from others with limited opportunities to interact with people outside their family. In fact, $74 \%$ of survey respondents say they rarely or never communicate face-to-face with other people who use platforms. ... Isolation from other workers is also a barrier to the potential for workers to communicate and therefore construct collective identities, a shared sense of interests and solidarity. This, in turn, reduces the ability of workers to collectively voice shared concerns regarding issues such as low wages. $94 \%$ of workers said they are not involved in any sort of labour union or worker association. (10)

These findings support our hypotheses that face-to-face perceptual and bodily interaction are important for learning, as Hobsbawm put it, "the habit of solidarity," and that social objects formed through communicative activity, in this case collective identities, provide durability to nascent solidarity relations. Prior even to reification in legal forms, social objects provide durability to "associative life" (Levin 2020): these objects allow associations to persist and be a reference point for individual and collective action outside of the immediate context of communication (hence the meaning of durability here). Small scale ethnographic work 
on platform delivery riders in the UK reported similar sentiments of disconnect with other workers based on high turnover of workers, disparate geographic placement, rotating shifts, and algorithmically mediated competition for "gigs" (work) (Warin 2017). ${ }^{20}$

The intersubjective backdrop of solidarity formation is further eroded by two other prominent features of algorithmically mediated platform work: platform identity construction and ADS evaluation/rating and distribution of work. To secure work, platform workers often construct identities that they think will appeal to clients or bypass certain biases, e.g., about quality of work done by workers residing in developing countries (Graham et al. 2017: 7). This creates a context where workers do not interact, if they interact at all, as their "true" off-platform bodily selves, but rather as platform avatars that may bear little resemblance to the people actually carrying out the work. We have argued that a horizon of expectation of predictable reciprocity of burden sharing is a condition of solidarity. This is greatly hampered by the need for platform labourers to construct platform specific identities. The geographical (or racial) biases of clients are not the direct result of ADS, but are facilitated by the capacity for a platform to algorithmically allocate tasks and matchmake between clients and independent contractors outside of the constraints of workplace anti-discrimination laws. ${ }^{21}$ The facilitation of client biases by ADS also creates class divisions among platform workers on the basis of location and profile rather than performance. A new form of "platform labour aristocracy" emerges, wherein privileged workers who are able to capture more work are then able to sub-contract tasks to "lower class" platform labourers (on the same platforms) at below market rates (Graham et al. 2017: 9).

A similar issue arises with algorithmic assessment of productivity, and the allocation of work or priority on the basis of these evaluations. Here the obstacle to solidarity formation was already laid out in Marx's 1844 manuscripts on alienation: by rendering workers as independent contractors labour platforms are able to place all in a competition with all. Opaque algorithmic ratings systems provide evaluation and algorithmic allocation of work is done on the basis of these ratings/ rankings. Constant and real-time evaluation of performance by often untransparent and unaccountable ADS creates competition and wage difference, again potentially limiting willingness to cooperate and pool risks/burden (Lee et al. 2015). The possibility of contract termination, resulting from ADS based evaluation, outside of standard labour laws regulating hiring and firing of employees in firms creates situations where all co-workers become potentially transient competitors. This phenomenon is not limited to independent contractors (gig workers), but also applies to ADS in performance evaluation within other contractual arrangements where workers may be employed with more traditional labour contracts (e.g., Jee 2020).

Further issues arise from the use of ratings systems to prioritise particular workers, allocate "gigs," and terminate contracts. Solidarity relations are "offen- 
sive" in character, that is, they are directed toward the transformation of political (legal and institutional) structures. Such structures can be understood as either inside or outside the firms. Management by ADS renders the decision-making structures that solidarity relations might aim to change opaque, untransparent, unaccountable, and sometimes proprietary in the sense of privately owned (the decision-making structures themselves are private property and protected under intellectual property law). Prassi (2018) cites Slee: "reputation systems fail in their basic task of distinguishing high quality or trustworthy offerings from lower-quality or untrustworthy offerings." They are instead "a substitute for a company management structure, and a bad one at that. A reputation system is the boss from hell: an erratic, bad-tempered and unaccountable manager that may fire you at any time, on a whim, with no appeal" (Slee 2015: 100-01). ADS deprives workers and subsequently solidarity relations of an understandable process or human judgement as a target. ADS management allows for the dispersal of decisions that are adverse to workers into a system with no human judgement that can be opposed or even understood.

Controls are not always diktats handed down to workers by ADS management systems but can also take the form of "soft control," "nudges" or even gamification (see Koivisto and Hamari 2019 for a review of gamification and motivational systems). Firms can design the choice architecture of online web or app-based platforms to motivate certain behaviours in an indirect fashion (also to avoid the appearance of company policies that might reveal employee-employer-like relations) (Rosenblat \& Stark 2016). In such cases, worker behaviour is not the direct result of management decisions but is internalised as the result of workers' autonomous decision-making within a contractual relation that the worker can opt out of any time. This has the potential impact of negating the perception of injustice or a clear institutional management structure that can be opposed: motivators for solidarity relations.

\section{Conclusion}

The examples that we have discussed in section 5 pertain to ADS managed labour platform work and workers. But we think them to be sufficiently generalisable to support our claim that the increasing prevalence of ADS in the workplace gives cause for concern regarding the formation of solidarity relations, which have historically been the primary mechanism for workers, and subsequently the broader population, to secure both workplace and broader civil and political rights. The use of ADS in task allocation, hiring, evaluation, process, and workflow management is not limited to labour platforms, though these have been the vanguard. ${ }^{22}$ Moreover, while most full-time workers continue to work within "traditional" employee-employer employment structures (JRC 2019), the 
number of independent contractors and online labour platforms using forms of ADS for "gig" allocation are growing. We speculate that the use of ADS for dispersed work management will increase following the COVID crisis, both in and outside the context of labour platforms. This will accelerate trends towards "flexible" "teleworking" and lessen the role of the fixed workplace where workers encounter one another in bodily form and communicate. We have characterised solidarity as a type of intersubjective experience and relation that has certain essential characteristics: expectation of reciprocal burden sharing, perception of injustice, political and offensive character. We have also emphasised the double role of "social objects" in solidarity relations, insofar as a solidarity relation is itself a social object and as solidarity relations are solidified or buttressed by other social objects. We've grounded our characterisation of solidarity on a historical, conceptual, and phenomenological analysis. On these grounds we've also argued that despite possibilities of "bad" solidarity, solidarity is a central characteristic of democratic society, both from a historical and a normative perspective. Critically we've also argued that the appearance of solidarity relations is subject to technological mediation. That is, certain socio-technical contexts display greater affinity for the formation of solidarity relations than others. Threats to the formation of solidarity relations in the workplace result from technological change, and ADS management are thus of broad political concern. We have not addressed possibilities for new forms of solidarity relations that emerge with increased global connectivity through algorithmically governed social media platforms and networks. Nor have we discussed how technological changes attributed to the "future-of-work" question broadly speaking are related to other phenomena which may impact forms of solidarity related to the structures of work, but not situated clearly within the world of work, for example how regional job polarisation impacts national- or locality-based solidarities. These are topics for future research.

Darian Meacham, Maastricht University Francesco Tava, University of the West of England

\section{Notes}

1. Technological unemployment pertains to the displacement of workers from the labour market as a result of technological changes, specifically the automation of tasks and roles. The term was first used by J. M. Keynes in the essay "Economic Possibilities for our Grandchildren” (Keynes 1963 [1930]). Technological unemployment can be temporary as displaced workers find employment in other or new sectors of the market, or can become "structural" if displaced workers are unable to re-enter the 
workforce due to a lack of skills. Estimates of future technological unemployment vary widely in the economic literature (see JRC 2019: 13-29 for an overview).

2. Labour-market or job polarisation refers to changes in the labour market wherein job growth happens at the two "poles" of the market: high skill/high pay and low skill/low pay. Polarisation is linked to rising rates of economic and social inequality. Polarisation is well documented in the US (Autor and Dorn 2013; Dvorkin and Shell 2017) and EU labour markets (Breemersch, Damijan, and Konings 2017).

3. Most multi-party political representation systems in Europe are currently structured around societal groups that emerged with the processes of modernisation and industrialisation, e.g., Labourers, Socialists and Social Democrats, Liberal bourgeois, etc.

4. The history of automation technologies in industrial workplaces can be understood as a two-pronged effort to increase productivity and decrease labour costs through deskilling and in the early phase of industrialisation the use of low-skilled child and female labour that had less (or no) leverage for demanding concessions (see for example Hobsbawm 1964: 292). At present, port automation is one recent example of automation technologies being used to circumvent labour organisation by human workers: "In the fiercely competitive and margin-pressed world of shipping, terminals and local economies cannot afford to be at the mercy of labor, any more than they can afford to rely on even the best productivity provided by a mostly human workforce. ... All that technology will require a new, albeit smaller class of highly paid, skilled workers able to run and repair the robots, automated cranes and unmanned vehicles" (Keefe 2015); another recent example is the Edunity webtool which allows members of New York State public unions to easily opt out of paying dues (https://edunity.io/). The right-wing not-for-profit Lincoln Network that designed the software describes it as: "an unsubscribe button from public sector unions." In partnership with several SPN member organizations, Lincoln designed and developed a technology platform to handle the end-to-end opt-out process from a public-sector union and provide leaving union members competitive benefits. Edunity is 100 percent digital. The flexible opt-out workflow feature is plug-and-play, and it can break through any type of barrier a union builds to prevent an opt-out. Edunity can easily be white-labeled for a specific locality or a discrete type of union" (see https://spn.org/lincoln-network-launches-edunity/).

5. We are using the term work here more of less synonymously with "employment," this is of course a limited use of the term because it excludes housework, care work, or other forms of voluntary work that are unremunerated and take place outside of the formal structure of organisations (public, private, or mixed) and firms that engage (and pay) workers (whom they don't always call employees) in formal or informal contractual relations. These other forms of work must obviously be included in any general definition. Following Dejours et al. (2018) we find Alfred Marshall's definition of labour as "an exertion of mind or body undergone partly or wholly with a view to some other good than the pleasure derived from [it]" (Marshall 1961) to be an appropriate general definition. In their 2019 opinion on the future-of-work the European Group on Ethics in Science and New Technology (EGE 2019) provides the following more general definition of "work": "work is a practice by which people (besides seeking to ensure that their own tangible and intangible needs are met) contribute something to their families, communities, or societies. 
6. Solidarity among workers, which gave rise to the various strains of socialist and social democratic solidarity is only one of the traditions of solidarity that emerged throughout the nineteenth century. Alternative concepts of solidarity may be found in Christian social ethics and in anarchism. For an overview of the history of solidarity in Europe, see Stjernø 2005. Despite their differences, all these traditions share the same assumption that solidarity is a form of gratuitous (in the sense of without charge) collaboration between people considering each other as moral equals.

7. Prainsack and Buyx (2017: 56) described this "solidification" as the third "tier" of solidarity relations ("Tier 3 Contractual, Legar, or Administrative Norms"). On the relationship between solidarity and legal domains and institutions (with a special focus on EU law) see Dagilytė 2018.

8. This vision echoes Rawls's theory of justice, according to which solidarity (or "fraternity" in Rawls's wording) is not a political concept insofar as it does not define any democratic right, but merely facilitates the comprehension of values stemming from democratic rights by spreading "certain attitudes of mind and forms or conduct" (Rawls 1999: 52).For a critique of Rawls's conception of fraternity and distributive justice, see for instance Cohen 1997; Estlund 1998.

9. When we refer to justice and injustice, we do not mean any specific theory of justice or juridical system, but the perception of such phenomena that individuals and groups can have as part of their lifeworld experience, and to the meanings and values that they form from such perception.

10. On Arendt's account of solidarity, see Allen 1999; Butler 2010; Gaffney 2018; Reshaur 1992.

11. The term "labour aristocracy" seems to have been introduced by the Russian Anarchist Mikhail Bakunin in 1872, when he wrote: "To me the flower of the proletariat is not, as it is to the Marxists, the upper layer, the aristocracy of labor, those who are the most cultured, who earn more and live more comfortably than all the other workers" (Bakunin 1872).

12. The European Union's General Data Protection Regulation (GDPR) defines automated individual decision-making as "a decision based solely on automated processing” (see art 22(1) of the General Data Protection Regulation).

13. The European Parliament's Scientific Foresite Unit refers specifically to "Algorithmic decision systems" (ADS) (Castelluccia and Le Métayer 2019). We prefer "Algorithmic Decision Support" systems because it indicates more clearly that the automation in questions supports decisions, sometimes replacing human decisions, sometimes structuring choice architecture, sometimes offering suggestions.

14. https://www.ohchr.org/EN/NewsEvents/Pages/DisplayNews.aspx?NewsID $=25522 \&$ LangID $=$ E.

15. Graham et al. (2017:2) define online gig work as: "paid work allocated and delivered by way of internet platforms without an explicit or implicit contract for long-term employment."

16. We refer here to the definition of collective bargaining operative in European Law, see https://www.Eurofound.europa.eu/efemiredictionary/collective -bargaining-autonomy.

17. Courts and tribunals in Belgium, Valencia, Madrid, London, and recently the UK Supreme Court have ruled that platform workers cannot be classified as independent 
contractors (De Stefano 2018) (see https://www.supremecourt.uk/press-summary/ uksc-2019-0029.html on UK Supreme Court decision). The European Trade Union Congress has referred to this difficulty in defining the status of labour platforms and platform workers as the "platform paradox": "platform economy operators present themselves as marketplaces even though in reality they often act like traditional employers. Instead of passive matchmaking, platforms rely on rating systems and algorithmic control to ensure that each aspect of the worker's task is completed in compliance with company policy and customer instructions" (Prassi 2018).

18. Prassi (2018) cites: Central Arbitration Committee: Trade Union and Labour Relations (Consolidation) Act 1992 Schedule A1-Collective Bargaining: Recognition Decision On Whether To Accept The Application (Case Number: TUR1/985(2016), 14 November 2017) at paragraph [133] available at https://assets.publishing.service. gov.uk/government/uploads/system/uploads/attachment_data/file/663126/Acceptance_Decision.pdf.

19. An important question here is how the ADS facilitated structure described differs from a traditional, for example, taxi company, where independent contractor drivers are dispatched by a centralised dispatch office. In the case of taxi or "ride sharing" services there are many similarities. There are however significant differences. ADS facilitates larger and more decentralised economies of scale. These structures, to remain with the taxi example, do not have a central dispatch that makes decisions. Responsibility for decision making (allocation of jobs) is distributed throughout the systems and further obfuscated by proprietary ADS technologies. Data-driven systems in this sector are also increasingly free from monopoly protecting regulations and high entry conditions (e.g., taxi "medallions") allowing for the amount of labour on the market to be controlled algorithmically, rather than politically, reducing the political leverage of the platform workers (see Cant 2019 for specific examples of this). The possibility to work as few or as many hours as one wishes-also algorithmically facilitated-changes the "stakes" and context for individual workers or groups of workers. This lack of physical loci of management activities, dispersion and obfuscation of responsibility for decision-making across a proprietary algorithmic network, loosening of regulation and entry criteria into the market resulting in an increase in the potential labour market, creation of workers with different stakes (though performing the same task within the same firm) all differentiate ADS facilitated labour platforms from their predecessors and all introduce further impediments to the formation of solidarity relations (we're grateful to an anonymous reviewer for asking for clarification on this point).

20. Warin's (2017) analysis points out these phenomena occurring despite some modicum of fate-to-face interaction between platform workers. Cant (2019) has also documented the development of organisational networks across Deliveroo riders using digital social media tools also highly reliant on ADS.

21. Platforms are not able to police the contracting preferences or biases of labour purchasers.

22. Eurofound (a European Union agency) reports that in 2018: "around 2\% of the European working-age population (aged 16-74) in 14 Member States are engaged in platform work as a main job. For around $6 \%$, platform work generates a significant income (at least $25 \%$ of the average wage for a standard working week of 40 hours), 
and almost $8 \%$ perform tasks through digital platforms at least once a month. National data show wide variations - from $0.3 \%$ to more than $20 \%$ of the population" (Eurofound 2018). Thus the proportion of the EU working age population performing platform labour is significant. Piasna (2020) provides a "critical assessment of different approaches to counting gigs; that is, estimating the scale of engagement in platform work in the general population." Moreover, we've argued throughout that while online labour platforms may be an exemplar of the phenomena we are concerned with, the use of ADS for supporting or managing work processes and human resource decisions extends beyond labour platforms.

\section{REFERENCES}

Acemoglu, Darren, and Pascual Restrepo. 2020. "Robots and Jobs: Evidence from US Labor Markets," Journal of Political Economy 128(6): 2188-2224. https://doi.org/10.1086/705716

Allen, Amy. 1999. "Solidarity after Identity Politics: Hannah Arendt and the Power of Feminist Theory," Philosophy and Social Criticism 25(1): 97-118. https://doi.org/10.1177/019145379902500105

Arendt, Hannah. 1990. On Revolution. London: Penguin.

Autor, David H., and David Dorn. 2013. "The Growth of Low-Skill Service Jobs and the Polarization of the U.S. Labor Market," The American Economic Review 103(5): 1553-97. www.aeaweb.org/articles?id=10.1257/000282806777212620. https://doi.org/10.1257/aer.103.5.1553

Bakunin, Mikhail. 1872. "On the International Workingmen's Association and Karl Marx." Available at https://www.marxists.org/reference/archive/bakunin/works/1872/ karl-marx.htm.

Breemersch, Koen, Joze P. Damijan, and Jozef Konings. 2017. "What Drives Labor Market Polarization in Advanced Countries? The Role of China and Technology." VIVES discussion paper n61. Available at https://feb.kuleuven.be/VIVES/publications/ discussion_papers/dp2017/vives-discussion-paper-61-labor-market-polarization.

Butler, Samuel A. 2010. "Arendt and Aristotle on Equality, Leisure, and Solidarity," Journal of Social Philosophy 41(4): 470-90. https://doi.org/10.1111/j.1467-9833.2010.01511.x

Cant, Callum. 2020. Riding for Deliveroo: Resistance in the New Economy. Cambridge: Polity Press.

Castelluccia, Claudia, and Daniel Le Métayer. 2019. "Understanding Algorithmic Decision-Making: Opportunities and Challenges," Panel for the Future of Science and Technology (STOA) and managed by the Scientific Foresight Unit within the Directorate-General for Parliamentary Research Services (DG EPRS) of the Secretariat of the European Parliament. EPRS/European Parliamentary Research Service Scientific Foresight Unit (STOA) PE 624.241. https://www.europarl.europa.eu/ RegData/etudes/STUD/2019/624261/EPRS_STU(2019)624261(ANN1)_EN.pdf. 
Cohen, G. A. 1997. "Where the Action Is: On the Site of Distributive Justice," Philosophy \& Public Affairs 26: 3-30. https://doi.org/10.1111/j.1088-4963.1997.tb00048.x

Cope, Zak. 2012. Divided World Divided Class: Global Political Economy and the Stratification of Labour Under Capitalism. Montreal: Kersplebedeb.

Dagilyte, Eglè. 2018. "Solidarity: A General Principle of EU Law? Two Variations on the Solidarity Theme," in Solidarity in EU Law: Legal Principle in the Making, ed. Andrea Biondi, Eglè Dagilyté, and Esin Küçük, 61-90. Northampton, MA: Edward Elgar Publishing. https://doi.org/10.4337/9781783477784.00009

Dejours, Christophe, Jean-Philippe Deranty, Emmanuel Renault, and Nicholas H. Smith. 2018. The Return of Work in Critical Theory: Self, Society, Politics. New York: Columbia University Press.

De Stefano, Valerio. 2018. "Labor Law, Privacy, Regulating Platform Work and Labour Protection: Flexibility Is Not Enough," in Regulating for Globalization Trade, Labor and EU Law Perspectives Regulating for Globalization. http://regulatingforglobalization .com/2018/05/23/platform-work-labour-protection-flexibility-not-enough/?doing wp_cron $=1591541336.5382490158081054687500$.

Durkheim, Emile. 1893. The Division of Labour in Society. London: Macmillan.

Dvorkin, Maximiliano A., and Hannah G. Shell. 2017. "Labor Market Polarization: How Does the District Compare with the Nation?," in The Regional Economist: Federal Reserve Bank of St Louis. https://www.stlouisfed.org/publications/regional-economist/ second-quarter-2017/labor-market-polarization-how-does-the-district-compare -with-the-nation.

Estlund, David. 1998. "Debate: Liberalism, Equality, and Fraternity in Cohen's Critique of Rawls," The Journal of Political Philosophy 6(1): 99-112. https://doi.org/10.1111/1467-9760.00048

Eurofound. 2018. "Employment and Working Conditions of Selected Types of Platform Work." Luxembourg: Publications Office of the European Union.

Eurofound and ILO. 2017. Working Anytime, Anywhere: The Effects on the World of Work. Geneva: Publications Office of the European Union and the International Labour Office.

European Group on Ethics in Science and New Technologies (EGE). 2018. "Future of Work, Future of Society." European Commission Directorate-General for Research and Innovation Unit RTD.DDG1.02-Scientific Advice Mechanism.

Floridi, Luciano. 2014. The Fourth Revolution: How the Infosphere is Reshaping Human Reality. Oxford: Oxford University Press.

Frey, Carl. 2019. The Technology Trap. Princeton, NJ: Princeton University Press.

Gaffney, Jennifer. 2017. "Solidarity in Dark Times: Arendt and Gadamer on the Politics of Appearance," Philosophy Compass 13(12): 1-13.

https://doi.org/10.1111/phc3.12554

Gould, Carol. 2014. Interactive Democracy: The Social Roots of Global Justice. Cambridge: Cambridge University Press. https://doi.org/10.1017/CBO9781139175999 
Graham, Mark, Vili Lehdonvirta, Alex Wood, Helena Barnard, Isis Hjorth, and David P. Simon. 2017. The Risks and Rewards of Online Gig Work at the Global Margins. Oxford: Oxford Internet Institute. Available at www.oii.ox.ac.uk/publications/gigwork.pdf. Gray, Robert. 1981. The Aristocracy of Labour in Nineteenth-Century Britain, c. 1850-1900. London: Macmillan. https://doi.org/10.1007/978-1-349-04198-5

Greenhouse, Steven. 2016. “On Demand, and Demanding Their Rights," The American Prospect Magazine. http://prospect.org/article/demand-and-demanding-their-rights.

Habermas, Jürgen. 1990. "Justice and Solidarity: On the Discussion Concerning 'Stage 6," in Hermeneutics and Critical Theory in Ethics and Politics, ed. M. Kelly. Cambridge, MA: MIT Press.

Habermas, Jürgen. 2013. “Democracy, Solidarity, and the European Crisis, Lecture delivered on 26 April 2013 at KU Leuven, Belgium. Available at https://www.pro-europa .eu/europe/jurgen-habermas-democracy-solidarity-and-the-european-crisis/.

Hobsbawm, Eric. 1952. “The Machine Breakers," Past and Present 1(1): 57-70. https://doi.org/10.1093/past/1.1.57

Hobsbawm, Eric. 1964. Labouring Men: Studies in the History of Labour. London: Weidenfeld and Nicolson.

Hobsbawm, Eric. 1975. The Age of Capital 1848-1875. London: Weidenfeld and Nicolson Ltd.

Jaume-Palasí, Lorena, and Matthias Spielkamp. 2017. "Ethics and Algorithmic Processes for Decision-Making and Decision Support," AlgorithmWatch Working Papers \#2. https://algorithmwatch.org/wp-content/uploads/2017/06/AlgorithmWatch_Work ing-Paper_No_2_Ethics_ADM.pdf.

Jee, Charlotte. 2020. "Amazon's System for Tracking Its Warehouse Workers Can Automatically Fire Them," MIT Technology Review Newsletter, 26 April 2020. https:// www.technologyreview.com/2019/04/26/1021/amazons-system-for-tracking-its -warehouse-workers-can-automatically-fire-them/.

Joint Research Centre (JRC). 2019. “The Changing Nature of Work and Skills in the Digital Age," JRC117505. Luxembourg: Publications Office of the European Union. Available at http://publications.jrc.ec.europa.eu/repository/handle/JRC117505. https://do.org/10.2760/679150

Keefe, Patricia. 2015. "Port Automation Puts Labor on Notice," Maritime Professional Q3. https://www.maritimeprofessional.com/magazine/story/201509/automation -labor-notice-499999.

Kerswell, Timothy. 2019. "A Conceptual History of the Labour Aristocracy: A Critical Review," Socialism and Democracy 33(1): 70-87. https://doi.org/10.1080/08854300.2018.1512816

Keynes, John Maynard. 1963. Essays in Persuasion, New York: W. W. Norton \& Co.

Koening, Gaspar. 2019. La fin de l'individu: voyage d'un philosophe au pays de l'intelligence artificielle. Paris: Editions de l'observatoire.

Koivisto, Jonna, and Juho Hamari. 2019. "The Rise of Motivational Information Systems: A Review of Gamification Research," International Journal of Information Management 45: 191-210. https://doi.org/10.1016/j.ijinfomgt.2018.10.013 
Kolers, Avery. 2012. "Dynamics of Solidarity", The Journal of Political Philosophy 20(4): 365-83. https://doi.org/10.1111/j.1467-9760.2010.00391.x

Larson, Jeff, Surya Mattu, Lauren Kirchner, and Julia Angwin. 2016. "How We Analyzed the COMPAS Recidivism Algorithm," ProPublica. https://www.propublica.org/ article/how-we-analyzed-the-compas-recidivism-algorithm.

Lee, Min Kyung, Daniel Kusbit, Evan Metsky, and Laura A. Dabbish. 2015. "Working with Machines: The Impact of Algorithmic and Data-Driven Management on $\mathrm{Hu}$ man Workers,' CHI '15: Proceedings of the 33rd Annual ACM Conference on Human Factors in Computing Systems: 1603-12. https://doi.org/10.1145/2702123.2702548

Leicht-Deobald, Ulrich, Thorsten Busch, Christoph Schank, Antoinette Weibel, Simon Schfheitle, Isabelle Wildhaber, and Gabriel Kasper. 2019. "The Challenges of Algorithm-Based HR Decision-Making for Personal Integrity," Journal of Business Ethics 160: 377-92. https://doi.org/10.1007/s10551-019-04204-w

Levin, Yuval. 2020. A Time to Build: From Family and Community to Congress and the Campus, How Recommitting to Our Institutions Can Revive the American Dream. New York: Basic Books

Marshall, Alfred. 1961. Principles of Economics, 8th ed. London: MacMillan.

Metz, Karl H. 1999. "Solidarity and History: Institutions and Social Concepts of Solidarity in 19th Century Western Europe," in Solidarity, ed. Kurt Bayertz, 191-207. Dordrecht: Kluwer. https://doi.org/10.1007/978-94-015-9245-1_10

Mittelstadt, Brent D., Patrick Allo, Mariarosaria Taddeo, Sandra Wachter, and Luciano Floridi. 2016. “The Ethics of Algorithms: Mapping the Debate," Big Data \& Society 3(2): 1-21 https://doi.org/10.1177/2053951716679679

Piasna, Agnieszka (2020). "Counting Gigs: How Can We Measure the Scale of Online Platform Work?," ETUI working paper 06.2020. Brussels: ETUI aisbl. https://doi.org/10.2139/ssrn.3699350

Prainsack, Barbara, and Alena Buyx. 2017. Solidarity in Biomedicine and Beyond. Cambridge: Cambridge University Press. https://doi.org/10.1017/9781139696593

Prainsack, Barbara, and Alena Buyx. 2018. "The Value of Work: Addressing the Future of Work through the Lens of Solidarity," Bioethics 32: 585-92. https://doi.org/10.1111/bioe.12507

Prassi, Jeremias. 2018. Collective Voice in the Platform Economy: Challenges, Opportunities, Solutions. Brussels: European Trade Union Confederation. https://www.etuc .org/sites/default/files/publication/file/2018-09/Prassl\%20report\%20maquette.pdf.

Reshaur, Ken. 1992. "Concepts of Solidarity in the Political Theory of Hannah Arendt," Canadian Journal of Political Science 25(4): 723-36. https://doi.org/10.1017/S0008423900004479

Resolutions of the Congress of Geneva. 1866. Available at https://archive.org/details/ resolutionsofcon00inte/page/2.

Rosenblat, Alex, and Luke Stark. 2016. "Algorithmic Labor and Information Asymmetries: A Case Study of Uber's Drivers," International Journal of Communication 10: 3758-75. 
Sack, Adam J. 2018. "Like Voting Rights? Thank a Socialist," The Jacobin Magazine, 21 December. Available at https://www.jacobinmag.com/2018/12/workers-movement -universal-suffrage-socialism-second-international.

Slee, Tom. 2015. What's Yours Is Mine: Against the Sharing Economy. New York: O/R Books. https://doi.org/10.2307/j.ctt1bkm65n

Spielkamp, Matthias. 2019. "Automating Society: Taking Stock of Automated DecisionMaking in the EUA.” Report by AlgorithmWatch in cooperation with Bertelsmann Stiftung, supported by the Open Society Foundations. Available at www.algorithm watch.org/automating-society.

Srnicek, Nick. 2017. Platform Capitalism. Cambridge: Polity Press.

Stjernø, Steinar. 2005. Solidarity in Europe: The History of an Idea. Cambridge: Cambridge University Press. https://doi.org/10.1017/CBO9780511490378

Warin, Robbie. 2017. "Dinner for One? A Report on Deliveroo Work in Brighton.” Autonomy Institute Research. https://autonomy.work/research/. 